\title{
Nurses' communication with dying children and their families in pediatric oncology: A literature review
}

\author{
Maryam Yadegari ${ }^{1}$, Janet Rankin ${ }^{2}$, Jessie M. Johnson*2 \\ ${ }^{1}$ Sidra Medicine, Doha, Qatar \\ ${ }^{2}$ Faculty of Nursing, University of Calgary, Calgary, Alberta, Canada
}

Received: August 29, 2018

DOI: $10.5430 /$ jnep.v9n2p37
Accepted: September 27, $2018 \quad$ Online Published: September 29, 2018

URL: https://doi.org/10.5430/jnep.v9n2p37

\begin{abstract}
The last period of life for a child dying from cancer is of critical importance, not only for the child, but also for the child's parents and other relatives. Health care professionals, especially nurses, face multiple challenges when caring for children dying from cancer. By better understanding the conversational topics that arise in the care of children dying from cancer and their families, nurses may best manage the communication challenges that arise during this difficult time of suffering. This literature reviews aim is to examine and gather evidence about topics that support nurses' communication when caring for children dying from cancer and their families. There are central conversations that pediatric oncology nurses should be comfortable with: death and dying; EOL decision making; symptoms and suffering. In pediatrics, play and playfulness should be maintained. Issues related to hope are integral to the parents' experience. Literature indicates that the involvement of palliative care teams improves the EOL experience for parents and children.
\end{abstract}

Key Words: Pediatric, Palliative, Oncology, Communication, End of life

A nurse working a night shift enters the room of a sleeping nine year old boy newly diagnosed with a late-stage of brain tumor. In the still darkness of the night his worried mother, who has kept an overnight vigil asks the nurse: "Will he die?"

Down the hall a fourteen year old girl who is close to death with bone cancer that has spread to her lung is breathing the jagged breaths that signal the final hours of life. Her frantic family is begging the nurse in charge to do something where nothing can be done.

These are examples of the difficult situations that nurses encounter whilst providing care for dying children. They invite nurses into difficult conversations.

\section{INTRODUCTION}

As reported by World Health Organization (WHO, 2016) "each year the prevalence of children diagnosed with cancera disease that touches all regions of the world and impacts countless families and communities" (para. 5) is $150,000 .{ }^{[1]}$ Nurses are integral to the care of children with cancer, both those for whom a cure is expected and for those children whose prognosis is poor and for whom end of life (EOL) or palliative care (PC) decisions are necessary. In their care of dying children, cancer nurses bear witness to, and engage with, people who are experiencing immense suffering. Nurses must be prepared to engage in difficult and sensitive discussions with dying children and their families. Canada.

*Correspondence: Jessie M. Johnson; Email: Jessie.Johnson1@ucalgary.ca; Address: Faculty of Nursing, University of Calgary, Calgary, Alberta, 
Purpose: Literature review on nurses' EOL communication

Nurses have an abiding presence in clinical settings where children with cancer are tended and nurses must be supported to respond effectively during the difficult conversations they encounter in end-of-life care. Nurses who have the skills to address the fear and grief that accompany serious illness, treatment, suffering, and death are a core resource to support children and families facing a life limiting cancer. Thus, the purpose of this review was to generate in depth knowledge that might offer practical guidance for nurses' therapeutic interactions with children dying from cancer and their families.

\section{METHOD}

This literature search was conducted on the Cumulative Index to Nursing Allied Health Literature (CINAHL), Medical Literature On-Line (MEDLINE) and PubMed data-bases. The search terms that generated the original search results cumulatively produced more than three hundred articles (Palliative or End-of-Life or Terminal or Dying, with the terms Communication and Oncolog* and Ped). These were screened for duplication and the inclusion criteria: English language papers, peer reviewed, published between 2006-2016, that included content on issues of communication in the care of infants and children, from birth to 18 years old, who have been diagnosed with a life limiting cancer. The screening resulted in 22 articles that were moved into the next level of review.

\section{Data analysis}

All 22 articles were assessed for scientific merit using appraisal tools appropriate to the method. Tools used for quantitative articles were appraised by critical appraisal tool for quantitative research studies; ${ }^{[2]}$ The Critical Appraisal Skills Program (CASP, 2013) ${ }^{[2]}$ was used for the qualitative studies. These two tools were applied respectively to each component of the two mixed methods research articles. CASP for systematic reviews was adapted to support our appraisal and subsequent inclusion of reviews. These two tools were applied respectively to each component of the mixed method research articles that was included in the review.

\section{Findings}

Most of the articles included in this review discussed communication in very abstract terms. They all emphasized that communication is a core feature of quality care. The papers focused on topics rather than skills. The findings point to the difficulty healthcare professionals encounter when raising difficult topics about death, symptoms, supportive care, hope and grief. The literature review indicated that the involvement of palliative care teams enhance the provision of care. As well this literature review described obstacles and supportive behaviors that influence EOL experiences of children and parents. Other features of communication that arose from this literature review were cultural considerations for families and children and the challenges that language barriers generate.

\subsection{Communication}

According to Franca et al. (2013) $)^{[3]}$ communication is the foundation of a human interaction. As such, it is the base for a relationship that permits nurses and other healthcare professionals to learn from the experiences of the child with cancer, and from the child's family to best understand their values and preferences. Incomplete, insensitive, or confusing communication is distressing to the ill child and to the family. ${ }^{[4]}$ Effective therapeutic communication in PPC/EOL contributes to improve QOL. ${ }^{[5,6]}$ Hendricks-Ferguson $(2015 b)^{[7]}$ emphasized that nurses and other health care professionals need support and education from experts in order to acquire effective PC/EOL communication skills necessary to engage in caring and sensitive discussions with dying children and their families.

\subsection{Communication and EOL decision making}

Health care providers need to understand EOL decision making from the parents' point of view and support parents' role as decision makers. ${ }^{[8]}$ In the reviewed articles EOL decisionmaking was most often explored as the purview of parents and physicians. There was also some advice about how to involve children (when appropriate) in EOL decision-making. Finding ways to include children in decisions emerged as an important communication value.

Assessment of children's and parent's perception of EOL care is critical in identifying the best care to be given. The importance of parents' perspectives and preferences was evident in two of the studies that found parents have a significant role in providing optimum quality of care to children dying from cancer. The systematic review of evidence by Montgomery et al. ${ }^{[9]}$ regarding parents' experiences along with the quantitative study of ${ }^{[4]}$ about parents' perspectives provides health professionals with an overall view of the critical importance of parental involvement in care planning and EOL decision making. Tomilson et al. (2011 ${ }^{[10]}$ reported that, despite healthcare professionals' advice, parents frequently preferred palliative chemotherapy in the care of their dying child because they hoped for both good quality of life and increase survival time. Within these highly sensitive decisions, nurses must ensure effective communication, 
not only between the nurses and family but also facilitating clear communication between the parents and physicians that are built on insights into parents' beliefs and perspectives. ${ }^{[9]}$ Nurses have the opportunity to assess and meet the needs of children and their parents during all phases of EOL, whether they are physical, emotional, or psychosocial in nature ${ }^{[4,9]}$

One of the parental preferences measured by Hechler et al. ${ }^{[4]}$ was that $88 \%$ of the parents preferred their child to die at home. This desire does not seem to be well supported, based on the chart review of Zhukovsky et al. ${ }^{[1]}$ who reported that the location of death was not a focus documented by the care team. Other small, but important findings about communication and EOL decision making include the findings of De Vos et al. ${ }^{[12]}$ who found that parents' involvement in EOL decision-making varied among various diagnosis. De Vos et al. ${ }^{[12]}$ claimed that, in cancer care, because of the strong relationships built among physicians and parents of dying children, physicians are more inclined to share overall responsibility of EOL decisions with parents (than with other life-limiting childhood illnesses). As well, in terms of supporting parents to make the best decisions that they can live with, Hechler et al. ${ }^{[4]}$ found $70 \%$ of parents would have decided against resuscitation in the EOL period, and $20 \%$ would have terminated medical care if these EOL discussions had been broached with more sensitivity.

\subsection{Communication and parental hope}

Parental hope is difficult for health care professionals to respond to. There are concerns that parents who remain hopeful may not understand the reality of their child's situation and that supporting parents to hope is somehow dishonest. The findings of Kamihara et al. (2015) ${ }^{[13]}$ contradict this view. Parents listened carefully to clinician's words about prognosis and nonetheless remained hopeful for their child even though they recognized the difficulties and different reality that their hope represented. This evidence represents simple yet compelling guidance for pediatric oncology nurses to improve EOL care for children by balancing honest information about prognosis while at the same time validating and supporting parents' expressions of hope. This can be communicated gently without words. Nurses' should be cautious about contradicting or correcting a parent's expression of hope - but rather should direct the conversation towards short-term goals and hopes. Hoping for a good quality of life and good quality of care is essential in assisting parents and the children during EOL care. ${ }^{[4]}$

\subsection{Communication and pain}

Communication was discussed as a critical component to be used in pain management. ${ }^{[9,14]}$ A child's pain is diffi- cult to assess. ${ }^{[14]}$ Having knowledge regarding the developmental levels of children contributes to how nurses and other healthcare professionals effectively manage the child's pain. ${ }^{[9]}$ Kars et al. $(2015)^{[15]}$ assessed parents' capacity to be their child's voice, as a critical component of providing good quality of care, which leads to good quality of life for children. One example that enhanced parental effectiveness was their ability to be with their child as much as possible in the hospital. This improved their capacity to be their child's voice when reporting pain and achieved enhanced pain management.

\subsection{Communication and the importance of play}

Soares et al.'s (2014) ${ }^{[17]}$ findings promote play as an effective means of communication with children in palliative care. The researchers stressed that even though the dying child might not be explicitly playful, "play is a necessity of childhood and the means by which it (the child) develops in all physical, emotional, cognitive and social aspects" (p.115). They recommended that nurses encourage playful, drawing, painting, and bedside story reading that can be used as nonphysically demanding strategies to engage children in play and that supports them to express their experience.

\subsection{Involvement of PPC teams and specialists during communication and care}

Research in the reviewed articles described the positive impact of a pediatric palliative care team in providing care to dying children and their families. The pediatric palliative care teams and their use of specific tools and communication elements improves the care of dying children and their families. ${ }^{[8,16]}$ In particular, the use of the decision support tool in the study by Kline et al. (2013) ${ }^{[8]}$ improved communication between families and health care providers and provided guidance for parents. For example the tool directed conversations towards the importance of the perception of the child's beliefs and wants, the child's level of discomfort or pain and the child's appearance or behavior. These features of communication enhanced how staff could formulate advice and it supported parents to make decisions that they could live with. Kassam et al. (2015) ${ }^{[16]}$ identified core elements of communication that direct best practices in the care for dying children and their families. These elements equip parents to talk to their child about death and dying, prepare parents for the medical aspects surrounding EOL, and provide siblings with support during difficult times. Palliative care consultations increase parents' level of comfort in healthcare professionals and facilitate discussions regarding death and dying in children with cancer. ${ }^{[15]}$ 


\subsection{Nurses' role in a child's dying and death}

Jantsch et al. (2012) ${ }^{[18]}$ reported that nurses are the healthcare professionals who have the most intimate experiences of children's dying and their death. They also reported that nurses face death with a certain amount of pragmatism while at the same time reporting difficulties in handling their emotions in relation to the death of a child they had come to know well. Nurses reported a variety of feelings toward caring for a dying child from cancer. ${ }^{[14]}$ Those feelings were sadness, helplessness and weakness to overcome their own anxieties and dilemmas that arise when providing ongoing support to the child and family. Not being able to reach the child within a therapeutic relationship influenced nurses' motivation in providing care to these children.

\section{Discussion}

In response to the broad aim of this literature review: To generate in depth knowledge that might offer practical guidance for nurses' therapeutic interactions with children dying from cancer (and their families), the review generated knowledge about the topics nurses must know about and be comfortable discussing. Honest, open, gentle conversation about death and dying is important. Nurses must be comfortable in raising and responding to questions about death, both at the time of prognosis and when death draws near. Parents should be told about what to expect and be supported. The pragmatics of symptom management, throughout the palliative journey is a core topic that nurses must understand and assess. Hope is a central experience for parents and hope should not be denied. Play is an important "communication tool" with children and nurses' playfulness should be an essential approach with children.

Nursing dying children is very challenging work. The broad literature on the topic of pediatric palliative care (not limited to terminal cancer) identified that nurses report a high degree of stress when caring for a dying child and when communicating with the child and the parent during the child's PC/EOL care. ${ }^{[18]}$ Davies et al. $(2008)^{[19]}$ reported that nurses struggle with the complexity of care and EOL decision making, they also struggle with their own grief and suffer moral distress when following physician's orders for treatments that imposed suffering without likely benefit to the dying child. Feudtner et al. (2007) ${ }^{[20]}$ surveyed pediatric nurses about their level of hope in provision of care to dying children and their families and revealed that nurses with a high level of hope were more comfortable in providing care to dying children and their families, and had less difficulty talking to children and their families about death and dying.

Nurses are engaged in every level of symptom management, including assessment, planning, delivery of intervention, and evaluation. Pediatric oncology nurses provide unique perspectives to manage symptoms at EOL. Pediatric oncology nurses' education must support high level development of specialized skills to assess and respond to fatigue, pain, loss of appetite, nausea, stomatitis, dyspnea and anxiety. Symptom management is a core feature of good palliative care. PC teams' role in referral and consultation is a key aspect of care evaluated in the literature. Wolfe et al. (2008) ${ }^{[21]}$ showed that PC consultation increases the detection and effective treatment of symptoms not identified by the primary health care professional team.

A critical EOL decision in pediatric oncology is the use of chemotherapy; it is a decision that can generate disagreements between health professionals and parents. Parents become focused on slowing the cancer progression (as opposed to symptom management). Data from Kreicbergs et al. $(2004)^{[22]}$ demonstrated that treating a child with chemotherapy until the very end of life is often accompanied by severe side effects that can trigger long lasting negative effects for the parents. Nurses must navigate the sensitive work of supporting hope, alleviating the child's suffering and supporting parents to come to compassionate decisions that they can live with.

A surprising finding from this literature review into nurses' communication in pediatric oncology EOL care was that the topic of grief was only superficially discussed in the reviewed articles. The death of a child is one of the most stressful events possible, and grieving is a lifelong process. Nurses' knowledge about grief is an important topic that nurses could begin to prepare parents for. Grief is a normal, dynamic, individualized process that encompasses physical, emotional, social, and spiritual aspects of persons who lose someone significant, with possible positive and negative consequences. ${ }^{[23]}$ Nurses who work in pediatric oncology should have a deep understanding of grief, how it works and how to support a grieving person.

\section{Conclusion}

PC and EOL communication should involve the child, family, and health care team. Nurses are in a central position in this involvement. It is critical to provide educational workshops within the nursing discipline in pediatric oncology to drive the attention of the nurses and raise their awareness toward provision of care to children dying from cancer and their families. Pediatric oncology nurses are situated in the clinical setting where conversations with dying children and their families happen. This literature review provides an important overview of topics related to childhood death that are central competencies for pediatric oncology nurses. 
Pediatric oncology nurses should have access to advanced education, support and mentorship to learn and acquire effective PC/EOL communication skills necessary to engage in caring and sensitive discussions with dying children and their families.

\section{REFERENCES}

[1] World Health Organization. 2016 International Childhood Cancer Day: 15 February 2016. Available from: http://www.who.int/ cancer/iccd_2016/en/

[2] CASP Tools and Checklist 2013. Available from: http://www.ca sp-uk.net/casp-tools-checklists

[3] França JRFDS, Costa SFGD, Lopes MEL, et al. The importance of communication in pediatric oncology palliative care: focus on $\mathrm{Hu}$ manistic Nursing Theory. Revista Latino-Americana de Enfermagem. 2013; 21(3): 780-786. PMid:23918025 https://doi.org/10.1 590/S0104-11692013000300018

[4] Hechler T, Blankenburg M, Friedrichsdorf SJ, et al. Parents' perspective on symptoms, quality of life, characteristics of death and end-of-life decisions for children dying from cancer. Klinische Padiatrie. 2008; 220(3): 166-174. PMid:18478489 https ://doi.org/ $10.1055 / \mathrm{s}-2008-1065347$

[5] Harrison J, Evan E, Hughes A, et al. Understanding communication among health care professionals regarding death and dying in pediatrics. Palliative and Supportive Care. 2014; 12(05): 387-392. PMid:23916065 https ://doi.org/10.1017/S1478951513000 229

[6] Wiener L, McConnell DG, Latella L, et al. Cultural and religious considerations in pediatric palliative care. Palliative and Supportive Care. 2013; 11(01): 47-67. PMid:22617619 https ://doi .org/10 $.1017 / \mathrm{S} 1478951511001027$

[7] Hendricks-Ferguson VL, Kane JR, Pradhan KR, et al. Evaluation of physician and nurse dyad training procedures to deliver a palliative and end-of-life communication intervention to parents of children with a brain tumor. Journal of Pediatric Oncology Nursing. 2015; 32(5): 337-347.

[8] Kline C, Reineke A, Auger J, et al. Effects of a unique pediatric hematology-oncology palliative care program on medical decision-making and communication between healthcare providers and families: Results of a supportive care survey. Progress in Palliative Care. 2013.

[9] Montgomery K, Sawin KJ, Hendricks-Ferguson VL. Experiences of Pediatric Oncology Patients and Their Parents at End of Life A Systematic Review. Journal of Pediatric Oncology Nursing. 2016; 33(2): 85-104. PMid:26219300 https ://doi.org/10.1177/10 43454215589715

[10] Tomlinson D, Bartels U, Gammon J, et al. Chemotherapy versus supportive care alone in pediatric palliative care for cancer: Comparing the preferences of parents and health care professionals. CMAJ: Canadian Medical Association Journal. 2011; 83(17): E1252-E1258.

[11] Zhukovsky DS, Herzog CE, Kaur G, et al. The impact of palliative care consultation on symptom assessment, communication needs, and palliative interventions in pediatric patients with cancer. Journal of Palliative Medicine. 2009; 12(4): 343349.
[12] de Vos MA, van der Heide A, Maurice-Stam H, et al. The process of end-of-life decision-making in pediatrics: a national survey in the Netherlands. Pediatrics. 2011; 127(4): e1004-e1012.

[13] Kamihara J, Nyborn JA, Olcese ME, et al. Parental hope for children with advanced cancer. Pediatrics. 2015; 135(5): 868-874. PMid:25847801 https://doi.org/10.1542/peds.2014-2855

[14] Javorski AR, Bushatsky M, Viaro VD. Palliative care in children with cancer: integrative review. Journal of Nursing UFPE. 2014; 9(2): 718-730.

[15] Kars MC, Grypdonck MH, de Bock LC, et al. The parents' ability to attend to the "voice of their child" with incurable cancer during the palliative phase. Health Psychology. 2015; 34(4): 446 PMid:25822058 https ://doi .org/10.1037/hea0000166

[16] Kassam A, Skiadaresis J, Alexander S, et al. Differences in end-oflife communication for children with advanced cancer who were referred to a palliative care team. Pediatric Blood \& Cancer. 2015; 62(8): 1409-1413. PMid:25882665 https://doi.org/10.1002/ pbc. 25530

[17] Soares VA, Silva LFD, Cursino EG, et al. The use of playing by the nursing staff on palliative care for children with cancer. Revista Gaúcha de Enfermagem. 2014; 35(3): 111-116. https : //doi.org/10.1590/1983-1447.2014.03.43224

[18] Jantsch LB, Neves ET, Arrué AM, et al. Palliative care in pediatric oncology: nursing contributions. Journal of Nursing UFPE. 2012; 6(7): 1706-1713

[19] Davies B, Sehring SA, Partridge JC, et al. Barriers to palliative care for children: perceptions of pediatric health care providers. Pediatrics. 2008; 121(2): 282-288. PMid:18245419 https : //doi .org/10.1 542/peds . 2006-3153

[20] Feudtner C, Santucci G, Feinstein JA, et al. Hopeful thinking and level of comfort regarding providing pediatric palliative care: a survey of hospital nurses. Pediatrics. 2007; 119(1): e186-e192.

[21] Wolfe J, Hammel JF, Edwards KE, et al. Easing of suffering in children with cancer at the end of life: is care changing? Journal of Clinical Oncology. 2008; 26(10): 1717-1723. PMid:18375901 https://doi.org/10.1200/JC0.2007.14.0277

[22] Kreicbergs U, Valdimarsdóttir U, Onelöv E, et al. Anxiety and depression in parents 4-9 years after the loss of a child owing to a malignancy: a population-based follow-up. Psychological Medicine. 2004; 34(08): 1431-1441. https://doi.org/10.1017/S00332 91704002740

[23] Hedayat K. When the spirit leaves: childhood death, grieving, and bereavement in Islam. Journal of Palliative Medicine. 2006; 9(6): 1282 1291. PMid:17187536 https ://doi.org/10.1089/jpm. 2006.9 .1282 